\title{
Revista Chilena de Nutrición. Estado actual
}

Durante el año 2016, el directorio de la SOCHINUT tomó la decisión de eliminar el formato en papel y hacerse completamente digital e iniciar el uso de plataforma Scielo para el envío de los aportes de los socios. Fue así como en diciembre de 2016, iniciamos esta transición, la cual se completó en el número 3 de 2017. A la fecha, hemos recibido más de 520 trabajos para ser sometidos a revisión por pares, con un promedio por sobre 18 manuscritos por mes.

Debido a este alto número de trabajos, el directorio de la SOCHINUT, en agosto de 2018, decidió por un lado, aumentar la frecuencia de aparición de nuestra revista a partir de 2019, es así como pasamos de 4 a 6 números por año y por otro lado, se aumentó la cantidad de manuscritos por cada número de la revista pasando de 10-12 a 16-18.

Cabe destacar, que si bien es cierto los principales colaboradores de nuestra revista son investigadores nacionales, recibimos manuscritos desde Perú, Argentina, Brasil, Colombia, Venezuela, México y España entre otros.

Por otro lado, tal como les contamos hace un tiempo atrás, la Revista Chilena de Nutrición ingresó a Web of Sciences, la antesala para poder posicionar a la Revista en el camino de obtener calificación ISI. En un comienzo, esta evaluación sería por un periodo de dos años, partiendo en abril de 2017. Sin embargo, cumplido el plazo, se nos hizo saber por parte de la entidad que esta evaluación se extendería hasta principios del año 2020. Esta decisión, que nos tomó por sorpresa, simplemente se debe a una sobre carga de los entes evaluadores, ya que el número de revistas que se encuentra en evaluación ha superado su capacidad de revisión.

Me despido de ustedes, invitándolos a seguir colaborando activamente con nuestra Revista y Sociedad, de tal forma de seguir creciendo y posicionar a nuestra revista como una referencia en la comunidad científica local como regional.

Miguel Arredondo Olguín
Editor Saliente
Revista Chilena de Nutrición
Prof. Titular
Instituto de Nutrición y Tecnología de los Alimentos, Universidad de Chile. 